\title{
Editorial
}

\section{Tiago Fazeres-Ferradosa}

CIIMAR - Interdisciplinary Centre of Marine and Environmental Research of the University of Porto, Marine Energy Research Group, Porto, Portugal: Hydraulics, Water Resources and Environmental Division, Department of Civil Engineering, Faculty of Engineering of the University of Porto, Porto, Portugal (email: tferradosa@fe.up.pt)

\section{Francisco Taveira Pinto}

CIIMAR - Interdisciplinary Centre of Marine and Environmental Research of the University of Porto, Marine Energy Research Group, Porto, Portugal; Hydraulics, Water Resources and Environmental Division, Department of Civil Engineering, Faculty of Engineering of the University of Porto, Porto, Portugal (email: fpinto@fe.up.pt)

\section{Paulo Rosa-Santos}

CIIMAR - Interdisciplinary Centre of Marine and Environmental Research of the University of Porto, Marine Energy Research Group, Porto, Portugal; Hydraulics, Water Resources and Environmental Division, Department of Civil Engineering, Faculty of Engineering of the University of Porto, Porto, Portugal (email: pjrsantos@fe.up.pt)
Over the past years, Maritime Engineering has consistently been a journal of many remarkable scientific contributions in numerous topics of Offshore and Coastal Engineering, as well as in other related topics of advanced research and practical applications in Maritime Engineering.

Owing to its track-record of publishing high-quality contributions, the year 2020 was no exception in spite of the challenging times faced due to the world's pandemic crisis, whose impacts also reached the 'realm of scientific publications'. Nevertheless, the number of submissions was still considerably high, which enabled a noteworthy gathering of scientific and applied case-study contributions that represent a meaningful impact in the development of Maritime Engineering. For the year 2021, the same mission remains: to keep on providing high-quality papers on the aforementioned topics to the scientific and professional communities.

As part of this mission, the first issue of this year is presented. As in several other published issues, - for example Correia et al. (2019a, 2019b, 2020a, 2020b), Fazeres-Ferradosa et al. (2019a, 2020) - there is a good balance between research and applied engineering papers, from practical cases to fundamental research. This issue brings us three interesting papers on the topics of Marine and Petroleum Geology (Yan et al., 2021), Statistics of Met-ocean Environment (Myrhaug and Lader, 2021) and Coastal and Maritime Structures (Melchers and Howlett, 2021).

On the first topic, Yan et al., (2021) provide an experimental modelling study concerning the pockmarks caused by gas hydrate decomposition by aeration. Often the decomposition of gas hydrates releases gas at large volumes, which escape violently, from deep submarine sediments. Not rarely, this results in significant changes in the seabed morphodynamics. For example, in natural gas hydrates, the decomposition of $1 \mathrm{~m}^{3}$ is converted to $164 \mathrm{~m}^{3}$ of gas and $0.8 \mathrm{~m}^{3}$ of water (Wang et al., 2018). Such volume expansion can lead to marine geological disasters, with pockmarks being one of them. In fact, the decomposition of gas hydrates is often pointed out as a cause of failure for submerged slopes (Nian et al., 2020). Failure of submarine slopes remains a marine/geological phenomenon which is, by far, less studied than other geotechnical related failures (Rhee, 2015). Through a physical model, Yan et al., (2021) showed that inflation in an underwater slope causes shear damage on the slope surface, with a venting channel eventually developing into a crater-like pockmark. Additional insights are given on the relationship between the sedimentation velocity and the flow velocity, the pore pressure at the slope and the influence of these variables in the submarine slope failure. This contribution provides an interesting topic that has considerable practical implications for numerous maritime structures and engineering operations, with a particular focus for those inherent to the exploitation of natural resources as oil and gas, namely in the stability of bottom-fixed structures (e.g. Paiva et al. (2020), Pavlou et al. (2019) or Seth et al. (2021)).

On another appealing theme, the statistical description and prediction of met-ocean data stand as a key topic to design marine structures at the nearshore (Goulby et al., 2017; Hames et al., 2019) and offshore locations (Fazeres-Ferradosa et al., 2018). A review of such statistical models is given, for example in Vanem et al. (2019), whereas practical applications are provided by Fazeres-Ferradosa et al., (2019b) and Hames et al., (2020). In the present issue, Myrhaug and Lafer (2021) provide us with a novel analytical method to estimate the random wave-induced drift in shallow waters within sea states, using deep-water wind statistics or deep-water wave statistics. In this new method, the wave-induced current in shallow waters is expressed in terms of the significant wave height and mean wave period. The method is then applied based on the metocean data from a deep-water location in the North Sea, but could be of added value to many other applications, namely, for nearshore drift-induced sediment transport, or even for matters related to the design of maritime structures under 
wave-induced current loads and associated phenomena - as scour at breakwaters (Kim et al., 1999) and other structures (Fazeres-Ferradosa et al., 2021) - or safety matters at nearshore locations (Hoguane et al., 2019). Myrhaug and Lafer (2021) method stands as a simple way to obtain preliminary estimations that might be used in practical cases, before diving into complex numerical models to propagate offshore conditions to nearshore locations.

Finally, a third contribution is given by Melchers and Howlett (2021), which present a remarkably interesting field case. This study concerns the corrosion phenomenon at the Phoenix caissons after 75 years of marine exposure. Near the coast of Arromanches (France), these reinforced concrete caissons endured a long period of marine immersion, tidal, splash and atmospheric conditions, from 1944 to nowadays. Therefore, this case study addresses a broad range of conditions over an unusually large period, which is not commonly reported in the literature. While giving a very interesting historical perspective on the caissons life cycle, Melchers and Howlett (2021) use observed data to derive important guidelines for the design of new reinforced concrete structures and the prediction of the remaining life of older marine exposed reinforced concrete structures. Additionally, this paper provides a clear photographic compendium that really shows the evident degradation of the caissons, along with several building pathologies. This article concludes that archival material from the Second World War revealed the caissons were designed to low safety margins and constructed at a very fast rate mostly with unskilled labour and minimal material usage. The concretes had a high cement content and were made with calcareous aggregates. Melchers and Howlett (2021) point out that these factors contributed to the high strength, low permeability, and high remaining alkalinity of the concretes and hence to the very low evidence of reinforcement corrosion. This paper stands as a worthwhile read for all practising coastal engineers.

As Maritime Engineering continues bringing to its readers meaningful contributions to a broad range of topics included in its scope of activity, the year 2021 is foreseen as another year full of interesting initiatives at our journal. Therefore, as a closure to this editorial, a chance is taken to advertise our next themed issue for 2021, 'Good practices for Coastal Erosion and Sea Level Rise Management'. This themed issue counts with the valuable expertise of the Leading Guest Editors, Professor Francisco Taveira Pinto and Professor Paulo Rosa Santos, from the Faculty of Engineering of the University of Porto (Portugal). It is a themed issue on a topic of crucial importance for all engineers, scientists and remaining professionals, who somehow deal with the matters of coastal morphodynamics, coastal protection and monitoring activities, climate change and sea level rise on coastal and nearshore regions, among other important issues embraced by the scope of coastal engineering towards sustainable management and responsible action to counteract the effects of sea-level rise.

\section{REFERENCES}

Correia JAFO, Mendes P, Fazeres-Ferradosa T and Zhu SP (2020a) Renewable energy and oceanic structures: part III. Proceedings of the Institution of Civil Engineers - Maritime Engineering 173(1): 1-2, https://doi.org/10.1680/jmaen.2020.173.1.1.

Correia JAFO, Fazeres-Ferradosa T, Zhu S and Zhu S (2020b) Renewable energy and oceanic structures: part IV. Proceedings of the Institution of Civil Engineers - Maritime Engineering 173(2): 31-32, https://doi.org/10.1680/jmaen.2020.173.2.30.

Correia JAFO, Ferradosa T, Castro JM, Fantuzzi N and Jesus AMPD (2019a) Editorial: renewable energy and oceanic structures: part I. Proceedings of the Institution of Civil Engineers Maritime Engineering 172(1): 1-2, https://doi.org/10.1680/ jmaen.2019.172.1.1.

Correia JAFO, Ferradosa T, Castro JM, Pavlou DG and De Jesus AMP (2019b) Editorial: renewable energy and oceanic structures: part II. Proceedings of the Institution of Civil Engineers Maritime Engineering 172(3): 71-72, https://doi.org/10.1680/ jmaen.2019.172.3.71.

Fazeres-Ferradosa T, Taveira-Pinto F, Vanem E, Reis MT and Neves LD (2018) Asymmetric copula-based distribution models for met-ocean data in offshore wind engineering applications. Wind Engineering 42(4): 304-334, https://doi.org/10.1177/0309524X18777323.

Fazeres-Ferradosa T, Rosa-Santos P, Taveira-Pinto F et al. (2019a) Editorial: advanced research on offshore structures and foundation design: part 1. Proceedings of the Institution of Civil Engineers Maritime Engineering 172(4): 118-123, https://doi.org/10.1680/ jmaen.2019.172.4.118.

Fazeres-Ferradosa T, Taveira-Pinto F, Romão X, Reis MT and Neves LD (2019b) Reliability assessment of offshore dynamic scour protections using copulas. Wind Engineering 43(5): 506-538, https://doi.org/10.1177/0309524X18807033.

Fazeres-Ferradosa T, Rosa-Santos P, Taveira-Pinto F et al. (2020) Preface: advanced research on offshore structures and foundation design: part 2. Proceedings of the Institution of Civil Engineers - Maritime Engineering 173(4): 96-99, https://doi.org/10.1680/jmaen.2020.173.4.96.

Fazeres-Ferradosa T, Chambel J, Taveira-Pinto F et al. (2021) Scour protections for offshore foundations of marine energy harvesting technologies: a review. Journal of Marine Science and Engineering 9(3): 297, https://doi.org/10.3390/jmse9030297.

Gouldby B, Wyncoll D, Panzeri M et al. (2017) Multivariate extreme value modelling of sea conditions around the coast of England. Proceedings of the Institution of Civil Engineers - Maritime Engineering 170(1): 3-20, https://doi.org/10.1680/jmaen.2016.16.

Hames DP, Gouldby BP and Hawkes PJ (2019). Evolution of joint probability methods in coastal engineering practice in the UK. Proceedings of the Institution of Civil Engineers - Maritime Engineering 172(2): 45-54, https://doi.org/10.1680/jmaen.2019.4.

Hames DP, Gouldby BP and Hawkes PJ (2020) Investigating the use of joint probability curves in coastal engineering practice. Proceedings of the Institution of Civil Engineers - Maritime Engineering 173(3): 68-78, https://doi.org/10.1680/jmaen.2019.12.

Hoguane AM, Gammelsrød T and Christensen KH (2019) Nearshore currents and safety to swimmers in Xai-Xai Beach. Journal of Integrated Coastal Zone Management 19(4): 209-220, https://doi.org/10.5894/RGCI-N148.

Kim H, Park W and O'Connor BA (1999) Scour at Sooyung Seawall caused by wave reflection and liquefaction. In 
Transactions on the Built Environment. WIT Press, vol 40, pp. 411-424.

Melchers RE and Howlett CM (2021) Reinforcement corrosion of the Phoenix caissons after 75 years of marine exposure. Proceedings of the Institution of Civil Engineers - Maritime Engineering 174(1): 19-30, https://doi.org/10.1680/jmaen.2019.19.

Myrhaug D and Lader PF (2021) Random wave-induced current in shallow water using deep-water wind and wave statistics. Proceedings of the Institution of Civil Engineers - Maritime Engineering 174(1): 11-18, https://doi.org/10.1680/jmaen.2019.9.

Nian T, Song X, Zhao W, Jiao HB and Guo X (2020) Submarine slope failure due to overpressure fluid associated with gas hydrate dissociation. Journal of Environmental Geotechnics, https://doi.org/ 10.1680/jenge. 19.00070.

Paiva PM, Junior JL, Calderon EN, Juliano MMF and Molisani MM (2020) Decommissioning of subsea oil and gas production pipelines: hydrodynamic modeling for preliminary assessment of sediment resuspension and burial onto benthic organisms. Journal of Integrated Coastal Zone Management 20(3): 161-168, https://doi.org/10.5894/RGCI-N286.

Pavlou DG and Correia JA (2019) Dynamic response of pipelines under impact and harmonic loading. Proceedings of the Institution of Civil Engineers - Maritime Engineering 172(1): 15-22, https://doi.org/10.1680/jmaen.2019.2.

Rhee CV (2015) Slope failure by unstable breaching. Proceedings of the Institution of Civil Engineers - Maritime Engineering 168(2): 84-92, https://doi.org/10.1680/maen.14.00006.

Seth D, Manna B, Kumar P et al. (2021) Uplift and lateral buckling failure mechanisms of offshore pipes buried in normally consolidated clay. Engineering Failure Analysis 121: 105161, https://doi.org/10.1016/j.engfailanal.2020.105161.

Vanem E, Fazeres-Ferradosa T, Rosa-Santos P and Taveira-Pinto F (2019) Statistical description and modelling of extreme ocean wave conditions. Proceedings of the Institution of Civil Engineers Maritime Engineering 172(4): 124-132, https://doi.org/10.1680/ jmaen.2019.20.

Wang Y, Feng JC, Li XS, Zhang Y and Han H (2018) Methane hydrate decomposition and sediment deformation in unconfined sediment with different types of concentrated hydrate accumulations by innovative experimental system. Applied Energy 226: 916-923.

Yan X, Xie W, Wei Z, Sun H and Wu G (2021) Experimental model of pockmarks from gas hydrate decomposition by aeration. Proceedings of the Institution of Civil Engineers - Maritime Engineering 174(1): 4-10, https://doi.org/10.1680/jmaen.2018.35. 